Article

\title{
Investigating Permeability of Coal Samples of Various Porosities under Stress Conditions
}

\author{
Mateusz Kudasik (D) \\ The Strata Mechanics Research Institute of the Polish Academy of Sciences, Reymonta 27, 30-059 Cracow, \\ Poland; kudasik@img-pan.krakow.pl; Tel.: +48-12-637-6200
}

Received: 15 January 2019; Accepted: 25 February 2019; Published: 25 February 2019

\begin{abstract}
Among the numerous factors that have an impact on coal permeability, coal porosity is one of the main parameters. A change in the mechanical stress applied to coal results in a change of porosity. The main objective of the conducted research was to answer the following question: is a decline in coal permeability a direct effect of a decrease in coal porosity, and does mechanical stress result solely in a porosity change? A study of coal porosity under mechanical stress conditions was conducted using a uniquely constructed measurement stand. The coal samples used were briquettes prepared from a granular coal material (middle-rank coal of type B-meta bituminous, upper carboniferous formation) from the "Zofiówka" coal mine, in Poland. In order to describe coal permeability, the Klinkenberg equation was used, as it takes into consideration the slippage effect, typical of porous media characterized by low permeability. On the basis of the obtained results, it was established that the values of the Klinkenberg permeability coefficient decrease as the mechanical stress and the corresponding reduction in porosity become greater. As the briquette porosity increased, the Klinkenberg slippage effect: (i) disappeared in the case of nitrogen, (ii) and was minor for methane. The briquettes used were characterized by various porosities and showed that mechanical stress results mainly in a change in coal porosity, which, in turn, reduces coal permeability.
\end{abstract}

Keywords: coal permeability; Klinkenberg slippage effect; permeability coefficient; methane; coal

\section{Introduction}

The phenomena of the sorption and transport of gases occurring in a solid-gas system are closely connected with the porous structure of sorbents. Bituminous coal is such a sorbent whose pores form a vast and irregular network [1]. The share of macro- and mesopores in coal is small, with these two types of pores playing the major role in the processes of transporting gases [2,3]. At the same time, micropores and ultramicropores with a diameter below $1 \mathrm{~nm}$, which constitute over $90 \%$ of the total pore space in coal, occupy a significant share in coal's porous structure $[4,5]$. Ultramicropores have dimensions comparable to the dimensions of individual gas particles, and are capable of altering their volume as a result of diffusion. However, the diffusion of gas within ultramicropores requires overcoming a substantial energy barrier, necessary to separate the walls of these pores [6,7].

The parameters describing the processes of accumulation and transport of gas in a coal are, respectively, the sorption capacity and diffusion and permeability [8]. The sorption capacity of coal is a parameter that describes in a quantitative way coal's ability to adsorb a sorbate. Diffusion and filtration, in turn, describe the kinetics of the process of transporting a sorbate within the pore space of a sorbent. These parameters always refer to specific conditions of the pressure and temperature of the coal-gas system [9]. Numerous scientific studies show that-apart from the thermodynamic conditions-the sorption capacity of coal and transport processes occurring in coal's pore space may be influenced by such properties as coal rank, maceral composition, type of the sorbed gas and presence of other sorbates [10]. Another parameter influencing the processes of sorption and transport of gas 
in coal is the mechanical stress applied to coal. The majority of the sorption studies performed on coal are carried out using granular samples, free of stress [11]. Under natural conditions, bituminous coal occurs in coal seams located at significant depths, often exceeding a thousand meters. Under such conditions, coal is affected by the geostatic pressure, which is dependent on the density of the overburden material and the depth (i.e., geothermal gradient and geostatic pressure). Therefore, under natural conditions, the sorption capacity, as well as the diffusion coefficient and permeability of coal affected by the geostatic pressure differ from the values of the same parameters determined in a laboratory, using stress-free coal.

Bituminous coal is characterized by a well-developed porous structure, and the process of gas sorption results in a change of this structure, which is caused by, among other things, sorption strain and swelling [12-18]. The swelling of coal, which accompanies sorption processes, reduces coal permeability $[12,19,20]$, while the shrinking of coal, accompanying desorption processes, increases coal permeability [21-23]. The number of the available studies of the swelling-sorption relationship in stress-affected coal is relatively small, and the available results show that stress applied to coal limits a coal's sorption swelling $[13,24]$.

The permeability of coal in relation to gases is a key parameter used to describe coal in the processes of fracturing CBM reservoirs in bituminous coal mines [25-27]. Laboratory measurements have shown that coal permeability decreases in an exponential manner as the effective stress increases [23,28-33]. Under the influence of the effective stress, the flow channels in pores and cracks of coal become narrower, and might even become totally closed, which, in turn, significantly reduces coal permeability [34]. Laboratory analyses have proven that the values of the coal permeability coefficient in relation to sorbed gases, such as $\mathrm{CH}_{4}$ and $\mathrm{CO}_{2}$, are lower than the values of the coal permeability coefficients in relation to non-sorbed or lightly sorbed gases, such as $\mathrm{Ar}$, He or $\mathrm{N}_{2}$ [21,35]. The permeability of coal decreases with the increase of the confining pressure exerted on the sample, with the value close to in situ conditions [34-36]. Among the numerous factors that have an impact on coal permeability, coal porosity is one of the main parameters neglected by previous studies. A change in the mechanical stress applied to coal results in a change of coal porosity. Thus, the following question arises: is a decline in coal permeability a direct effect of a decrease in coal porosity under the impact of stress? If so, then stress does not have a direct impact on coal permeability, but has an indirect effect, by reducing coal porosity. Answering that question was the main objective of the present research.

\section{Methodology}

\subsection{Technical Analyses of Coal}

The technical analyses of the coal destined for the research involved determining its porosity by means of establishing the skeletal and envelope densities of the lump samples of the investigated coal material. The skeletal density was determined by means of the helium pycnometry method, using the AccuPyc II 1340 analyzer (Micromeritics Instrument Corp, Norcross, GA, USA). With the known mass of the sample, the volume of helium $(\mathrm{He})$ penetrating the pore space of coal was measured. The measurement was performed at $298 \mathrm{~K}$. It was assumed that at this temperature, helium is a non-reactive gas, which is why its interaction with the surface of the sample could be neglected. The envelope density was determined by means of the quasi-liquid pycnometry method, using the GeoPyc 1360 analyzer (Micromeritics). That analysis was based on the measurement of the envelope volume of a lump sample under dry conditions, using the so-called DryFlo. Before the measurement, the coal sample was crushed to particles of irregular shapes with the diameter of about 10-20 mm. The sample of a known mass was placed in the chamber and the volume of the chamber together with the sample was identified. The volume of the sample was determined based on the difference between the volume of the empty chamber and the volume of the chamber containing the sample [37]. The measurement cycle was repeated ten times. 
Once the skeletal and envelope densities were known, porosity was calculated using the following formula:

$$
\phi=\left(1-\frac{\rho_{e}}{\rho_{s k}}\right) \cdot 100 \%,
$$

where: $\phi(\%)$-is the porosity, $\rho_{e}\left(\mathrm{~g} / \mathrm{cm}^{3}\right)$-is the envelope density, $\rho_{s k}\left(\mathrm{~g} / \mathrm{cm}^{3}\right)$-is the skeletal density.

\subsection{Describing the Phenomenon of Coal Permeability in Relation to Gas}

The physical processes occurring in the coal-gas system can be divided into proper sorption/desorption, diffusion, and filtration [8]. Proper sorption/desorption, understood as the change in the amount of degree of freedom of the gas molecules near the surface of the sorbent, depends mainly on the porous structure of coal and takes place in the smallest pores [8]. The diffusion phenomenon is related to changes in the kinetics of methane release/accumulation from/in coal, and it occurs mainly in micro- and ultramicropores. In fractures and macropores of coal, filtration of gas takes place, driven by the pore pressure gradient. The filtration process is analyzed as a phenomenon of fluid mechanics, and it can be approximately described using the Darcy equation for incompressible fluids [38]:

$$
v=-k \cdot \frac{d p}{d x}
$$

where: $v\left(\frac{\mathrm{m}}{\mathrm{s}}\right)$-is the filtration rate, $k=\frac{k_{g}}{\mu}\left(\frac{\mathrm{mD}}{\mathrm{Pa} \cdot \mathrm{s}}\right)$-is the filtration coefficient, $k_{g}(\mathrm{mD})$-is the (Darcy) permeability coefficient to gas, $\mu$ (Pa.s) -is the dynamic viscosity coefficient, $p(\mathrm{~Pa})$-is the pressure.

To determine the permeability coefficient $k_{g}$ of porous media for incompressible fluids, the Equation (1) should be transformed into the following formulas [39]:

$$
\begin{gathered}
Q=-\frac{k_{g}}{\mu} \cdot \frac{\left(p_{\text {out }}-p_{\text {in }}\right)}{l} \cdot A, \\
k_{g}=\frac{Q \cdot \mu \cdot l}{A \cdot\left(p_{\text {in }}-p_{\text {out }}\right)},
\end{gathered}
$$

where: $Q\left(\frac{\mathrm{m}^{3}}{\mathrm{~s}}\right)=v \cdot A$-is the flow rate, $A\left(\mathrm{~m}^{2}\right), l(\mathrm{~m})$-are the surface and length of the sample, $p_{\text {out }}, p_{\text {in }}(\mathrm{Pa})$ - are the outlet and inlet pressure of the fluid.

The permeability of porous media to compressible gas can be calculated according to another form of Darcy's equation [40]:

$$
k_{g}=\frac{2 \cdot Q \cdot p_{a t m} \cdot \mu \cdot l}{A \cdot\left(p_{\text {in }}{ }^{2}-p_{\text {out }}{ }^{2}\right)},
$$

where: $p_{a t m}(\mathrm{~Pa})$-is the atmospheric (reference) pressure.

In the case of bituminous coal, the flow of gas in its pore space is a very complicated process. Coal permeability to gases is higher than to liquids, due to slip effect between gas molecules and solid walls [39]. During the flow of gas molecules in the pores of coal, they collide with each other and with the walls of coal, and the frequency of these collisions increases with flow in smaller pores, due to decrease in the mean free path of the gas particles. Hence the slip effect on the pore walls, during gas flow through porous media with very small pores. This phenomenon is most often referred to as Klinkenberg's slippage effect (Figure 1), which results in an increase of the flow rate [39]:

$$
k_{g}=k_{\infty}\left(1+\frac{b}{p_{a v g}}\right)
$$

where: $k_{\infty}(\mathrm{mD})$-is the Klinkenberg absolute permeability coefficient under the infinite fluid pressure, $b(\mathrm{~Pa})$-is the Klinkenberg slippage factor, depending on the pore structure of the medium and 
the mean free path of gas particles, as well as the pressure of gas, its temperature and mole mass, $p_{\text {avg }}(\mathrm{Pa})=\frac{p_{\text {in }}+p_{\text {out }}}{2}$-is the average pressure of gas flowing through the sample.

a)

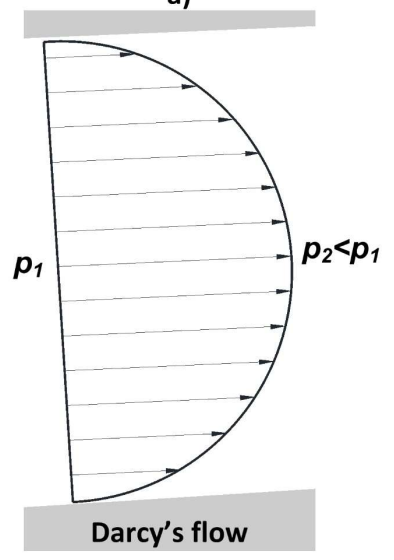

b)

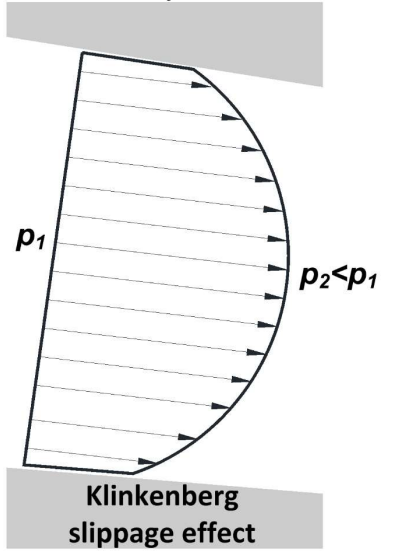

Figure 1. Gas flow in the pore space according to Darcy (a) and taking into account the Klinkenberg slippage effect (b).

The Klinkenberg absolute permeability $k_{\infty}$ and the Klinkenberg slippage factor $b$ can be determined using the linear dependence of the permeability coefficient $k_{g}$ on the reciprocal average pressure $1 / p_{\text {avg }}$ (Figure 2) [38].

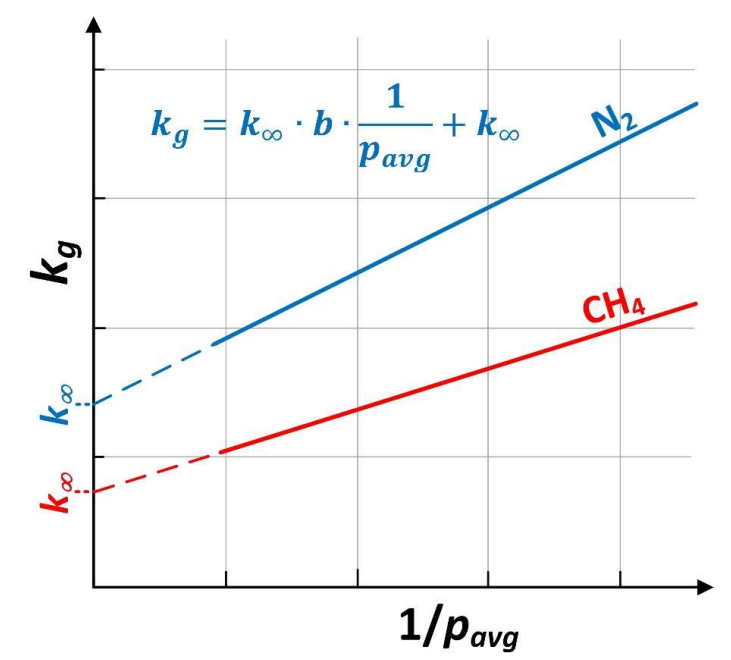

Figure 2. An example of the dependence of the permeability coefficient $k_{g}$ on the reciprocal average pressure $1 /$ pavg.

In the experiments, the permeability coefficients $k_{g}$ were determined from Equation (5). The Klinkenberg absolute permeability coefficients $k_{\infty}$ and the Klinkenberg slippage factors $b$ were determined by fitting - by means of the least squares method-Equation (6) to the experimentally obtained values of $k_{g}$ for different values of the average gas pressure in the samples.

\subsection{Measurement Stand for Studies into Permeability of Coal under Stress Conditions}

At the Strata Mechanics Institute of the Polish Academy of Sciences, innovative measurement instruments for investigating the rock-gas system have been constructed [41-49]. The permeability of coal under stress conditions was investigated using a novel measurement stand, whose schematic representation is provided by Figure 3, and a photograph in Figure 4. 


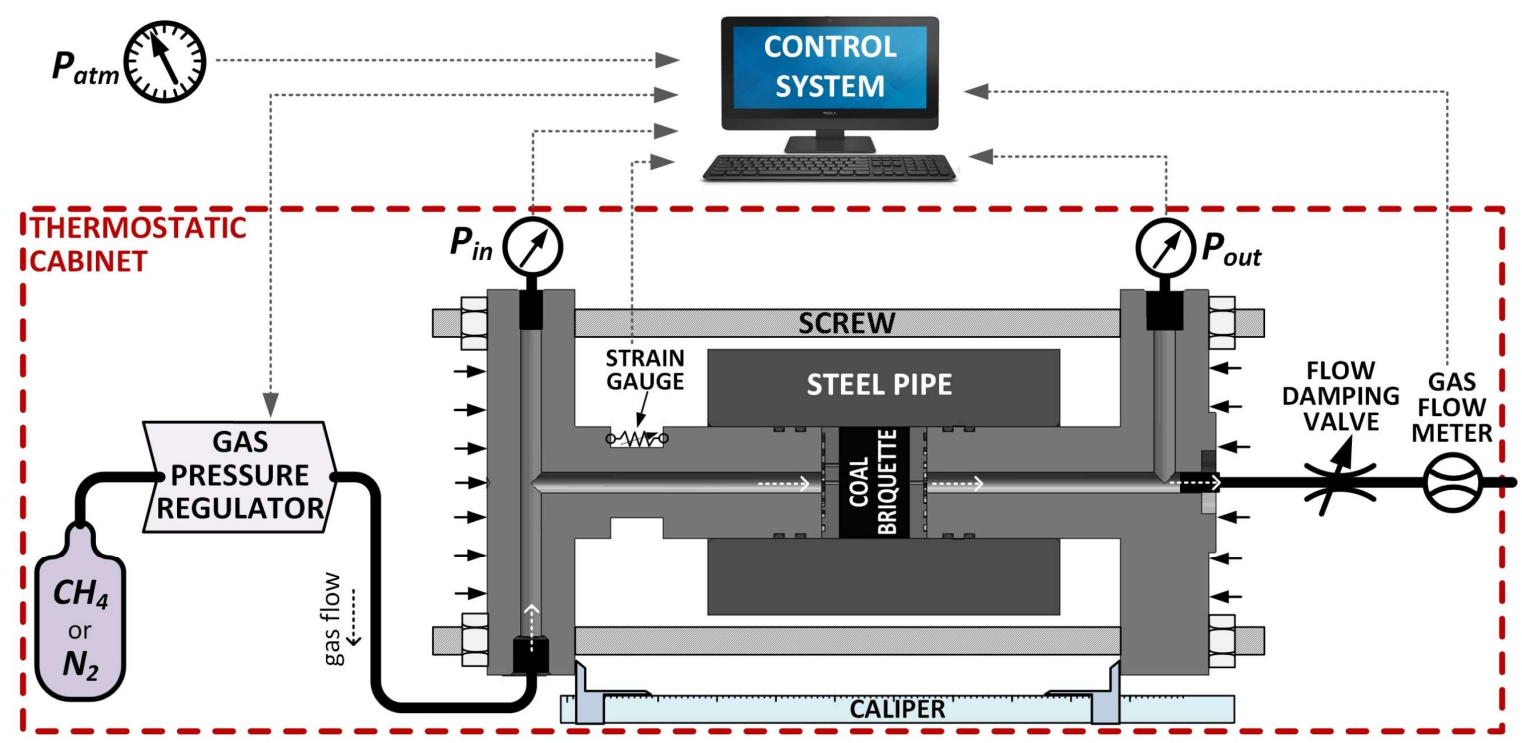

Figure 3. A scheme of the measurement stands for investigating coal permeability under stress conditions, where $P_{\text {in }}, P_{\text {out }}$-are the gas inlet and outlet pressure transducers; $P_{\text {atm }}$-is the barometer.

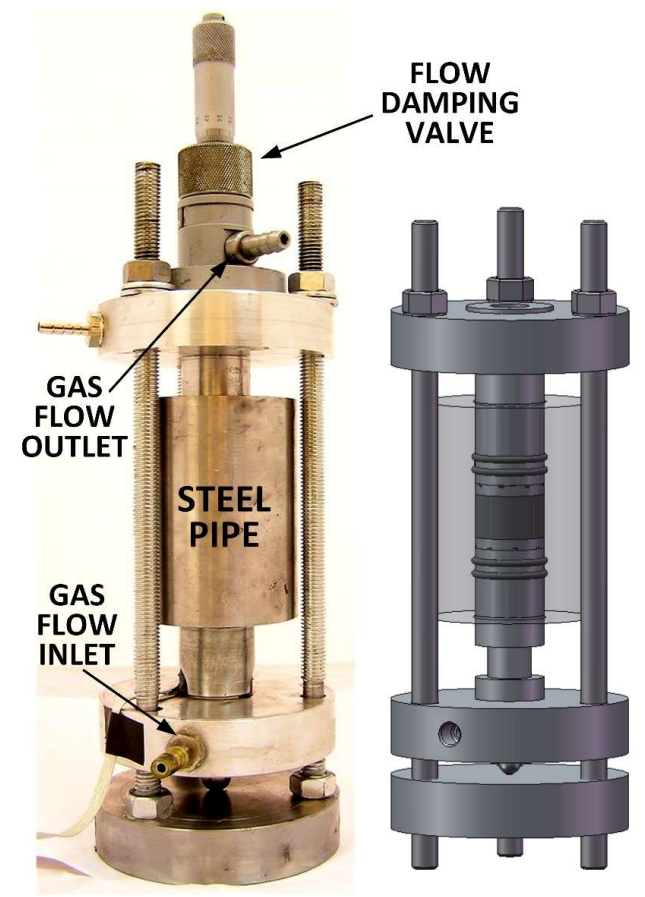

Figure 4. A photograph (left) and 3D model (right) of a part of the measurement stand for investigating coal permeability under stress conditions.

The constructed measurement stand makes it possible to investigate the permeability of coal samples under stress conditions. A coal sample is placed inside a thick-wall steel pipe with a hole diameter of $3.2 \mathrm{~cm}$ and length of $10 \mathrm{~cm}$. The sample is subjected to axial stress under conditions that prevent radial expansion. The stress is applied by aluminum pistons adjacent to the sample. The pressure from the pistons is generated by means of a screw press, and the stress is recorded by means of a strain gauge system (model SGM-1C, The Strata Mechanics Research Institute of the Polish Academy of Sciences, Poland) placed on the side of one of the pistons [48]. Through an inlet, gas under constant pressure is supplied using a precise pressure regulator [49]. At the outlet of the device, there is a regulated gas flow damping valve and a capillary gas flow meter with the measurement range of $0-1 \mathrm{Ncm}^{3} / \mathrm{s}$ [50]. The pressure at the inlet and outlet of the sample is measured using pressure 
transducers $P_{\text {in }}$ and $P_{\text {out }}$ (model S-20, WIKA, Klingenberg, Germany) with the measurement range of $0-16$ bar and the measurement accuracy of $\pm 0.125 \%$ of the full scale. A change in the porosity of the sample, proportional to the changes in its volume, occurring as a result of the changes in the stress applied to the sample, is established by means of the caliper measuring the distance between the pistons.

The isothermal conditions of the measurement are ensured by placing the measurement system inside a Q-Cell 60 thermostatic cabinet (Pol-Lab, Wilkowice, Poland), with the temperature adjustment range of $276-313 \mathrm{~K}$ and stability of $\pm 0.2 \mathrm{~K}$. During the measurement process, the atmospheric pressure is established using a barometer $P_{\text {atm }}$ (model LB-750B, LAB-EL, Reguły, Poland). Controlling the measurement system and registering the measurement data is achieved through a transducer card (model USB-4716, Advantech, Taipei, Taiwan) connected to a computer equipped with DasyLab software (measX, Moenchengladbach, Germany), which serves as a control system.

\subsection{Measurement Procedure}

Studies into the permeability of coal under stress conditions were conducted using two gases differing with respect to their sorption potential, i.e., nitrogen $\left(\mathrm{N}_{2}\right)$ and methane $\left(\mathrm{CH}_{4}\right)$. All the tests were carried out at $298 \mathrm{~K}$. The measurement procedure involved the following stages:

(1) Outgassing the sample to a vacuum $10^{-5}$ bar for $24 \mathrm{~h}$;

(2) Measurement of the sample's permeability of a particular gas $\left(\mathrm{N}_{2}\right.$ or $\left.\mathrm{CH}_{4}\right)$, encompassing two subs-stages:

2.1 Applying stress on the sample (0, 6, 12, 18, 24, $30 \mathrm{MPa})$;

2.2 Injecting the gas under specific measurement conditions (pressure at the sample's inlet and outlet) and waiting for the flow to stabilize, with the process repeated 5-8 times under various measurement conditions (by changing the pressure at the sample's inlet and outlet).

After sub-stage 2.2 was completed for a specific stress applied to the sample, the stress was increased again (sub-stage 2.1) and sub-stage 2.2 was performed again. After the maximum stress was reached and sub-stage 2.2 was completed, the sample was replaced with another one, having different initial porosity, and the entire procedure was repeated.

In order to establish the Klinkenberg absolute permeability coefficient $k_{\infty}$ and the Klinkenberg slippage factor $b$ of the sample, for specific measurement conditions (the type of gas and the value of stress applied to the sample), it was necessary to determine Darcy's permeability coefficient $k_{g}$. To this end-on the basis of the results obtained from the permeability measurement-Equation (5) was applied. Subsequently, on the basis of the relationship $k_{g}\left(1 / p_{\text {avg }}\right)$, determining the coefficients $k_{\infty}$ and $b$ became possible.

In order to determine the permeability coefficients $k_{g}$ of the sample, it was necessary to identify the following parameters during the measurement process:

- the gas pressure values at the inlet and outlet of the sample measured by the $P_{\text {in }}$ and $P_{\text {out }}$ pressure transducers,

- the gas flow rate measured by the gas flow meter,

- the atmospheric pressure measured by the barometer $P_{a t m}$.

Additionally, in order to determine the measurement conditions, the strain-proportional to the stress applied to the sample-was registered by means of a properly calibrated system of strain gauge. Moreover, for a specific value of the stress applied to the sample, the distance between the pistons was measured using the caliper, which made it possible to determine the porosity of the sample.

During the measurement, the pressure of gas at the inlet of the sample was regulated (within the $0.15-0.35 \mathrm{MPa}$ range), as well as the flow rate of gas at the outlet of the sample (within the 
$\left.0.05-0.50 \mathrm{Ncm}^{3} / \mathrm{s}\right)$. Under specific measurement conditions, after setting the proper level of pressure at the sample's inlet and the proper level of gas flow rate at the sample's outlet, it was necessary to wait to a steady flow rate of gas. For each permeability measurement, with a given gas used and a specific value of stress applied to the sample, 5-8 measurement points were registered, on the basis of which the relationship $k_{g}\left(1 / p_{\text {avg }}\right)$ was established. A sample course of the changes of the registered parameters for a single measurement procedure, along with the permeability coefficients $k_{g}$ obtained on that basis as a function of the inverse average pressure of gas in the sample, were presented in Figure 5. By fitting Equation (6) to the values of the permeability coefficients $k_{g}$ calculated from Equation (5), using the least squares method, the Klinkenberg absolute permeability coefficients $k_{\infty}$ and the Klinkenberg slippage factors $b$ were established.

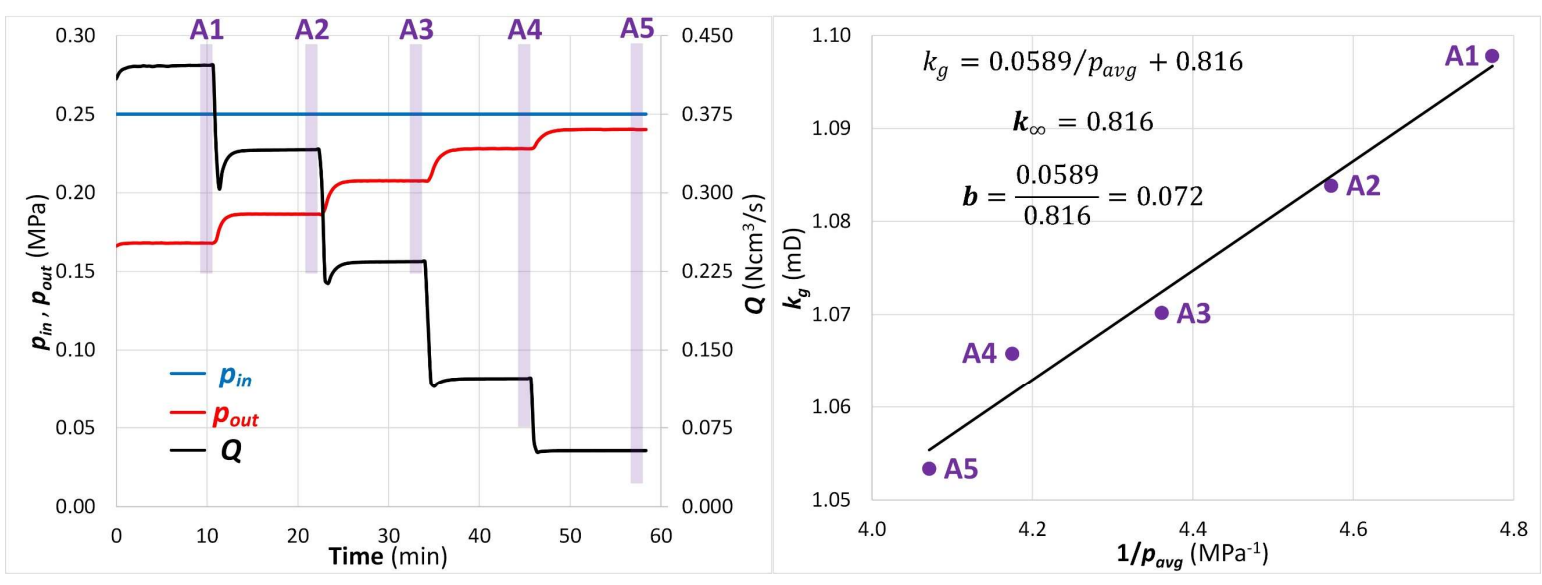

Figure 5. A sample course in the changes of the registered parameters for a single measurement procedure (with the sample porosity amounting to $18.87 \%$ and the stress value equaling $0 \mathrm{MPa}-$ the graph to the left) and the permeability coefficients $k_{g}$ obtained on that basis as a function of the reverse average pressure of gas in the sample (the graph to the right).

The procedure of determining the Klinkenberg permeability coefficients was similar, with the consecutive stress values applied to a sample.

\section{Research Material}

The permeability measurements were conducted using a bituminous coal sample from the "Zofiówka" coal mine in Poland, retrieved from the coal bed 409/4, section D. The seam 409/1 is deposited in upper carboniferous formation in Namurian C, Upper Silesian Sanstone Series, and belongs to Ruda beds. Selected parameters of the coal used in the research are presented in Table 1.

Table 1. Properties of the coal sample.

\begin{tabular}{ccccccc}
\hline \multicolumn{3}{c}{ Physical Properties } & \multicolumn{4}{c}{ Petrographic Analysis * } \\
\hline $\begin{array}{c}\rho_{e} \\
\left(\mathrm{~g} / \mathrm{cm}^{3}\right)\end{array}$ & $\begin{array}{c}\rho_{s k} \\
\left(\mathrm{~g} / \mathrm{cm}^{3}\right)\end{array}$ & $\begin{array}{c}\phi \\
(\%)\end{array}$ & $\begin{array}{c}R_{o} \\
(\%)\end{array}$ & $\begin{array}{c}\text { Vitrinite } \\
(\%)\end{array}$ & $\begin{array}{c}\text { Inertinite } \\
(\%)\end{array}$ & $\begin{array}{c}\text { Liptinite } \\
(\%)\end{array}$ \\
\hline 1.203 & 1.392 & 13.6 & 1.29 & 65.3 & 33.5 & 1.2 \\
\hline \multicolumn{5}{c}{ * based on [51]. }
\end{tabular}

According to the classification of coal based on the average vitrinite reflectance $R_{o}$, in line with the UN-ECE International Classification of In-Seam Coals [52], this particular coal represents middle-rank coal of type B (meta bituminous).

The coal samples used for the research were coal briquettes made from granular coal material (grain size $<0.2 \mathrm{~mm}$ ), which was pressed directly inside the measurement pipe. In total, 8 coal briquettes (with a diameter of $3.26 \mathrm{~cm}$ and a length of $1.89 \mathrm{~cm}$ to $2.08 \mathrm{~cm}$ ) characterized by various initial porosities 
were prepared. Four samples were selected for permeability tests using nitrogen, and the other four were used in permeability tests using methane. Selected parameters of the prepared samples are presented in Table 2. Before the start of each measurement, coal was dried in the temperature of $378 \mathrm{~K}$, to eliminate the hygroscopic humidity.

Table 2. Properties of the coal sample.

\begin{tabular}{ccccc}
\hline Sample Symbol & $\begin{array}{c}\text { Sample Pressing } \\
\text { Pressure (MPa) }\end{array}$ & $\begin{array}{c}\text { Slenderness Ratio } \\
\text { (Length/Diameter) }\end{array}$ & $\begin{array}{c}\text { Initial Porosity } \\
\mathbf{( \% )}\end{array}$ & $\begin{array}{c}\text { Type of Gas Used in } \\
\text { Permeability Tests }\end{array}$ \\
\hline N1 & 47.9 & 0.64 & 18.87 & \\
N2 & 71.9 & 0.62 & 15.81 & Nitrogen \\
N3 & 83.9 & 0.60 & 14.24 & \\
N4 & 95.8 & 0.59 & 12.91 & Methane \\
M1 & 83.9 & 0.62 & 14.41 & \\
M2 & 119.8 & 0.60 & 11.33 & 9.97 \\
M3 & 155.7 & 0.59 & 9.21 & \\
M4 & 191.7 & 0.58 & & \\
\hline
\end{tabular}

Preparing a sample characterized by a properly low value of the slenderness ratio ensured that the stress exerted on that sample during the axial compression approximated the oedometric stress conditions [53]. Each sample was pressed with a hydraulic press to its initial porosity, which changed during the measurement as a result of applying stress to the sample.

\section{Results}

As a result of the conducted experiments, the following parameters were analyzed:

- Darcy's permeability coefficients $k_{g}$ of coal briquettes, as depending on the average pressure $p_{a v g}$ of nitrogen and methane,

- the Klinkenberg absolute permeability coefficients $k_{\infty}$ of coal briquettes and the Klinkenberg slippage factors $b$, as depending on stress and coal porosity,

- $\quad$ the Klinkenberg permeability parameters ratio to nitrogen and methane.

\subsection{Darcy's Permeability Coefficients $k_{g}$}

According to the established measurement procedure, the values of the Darcy permeability coefficients $k_{g}$ under particular measurement conditions (stress $\sigma$ and porosity $\phi$ ) were determined using Equation (5), on the basis of the registered measurements of the coal briquettes' permeability to nitrogen and methane. The relationship between the Darcy permeability coefficients $k_{g}$ and the average gas pressure $p_{a v g}$ - where the value of $k_{g}$ decreases with rising pressure as a result of, among others, sorption swelling of coal [54,55], as well as the Klinkenberg effect declining along with pressure [56]—is widely known.

In order to determine the Klinkenberg permeability by means of the method described in Section 2.4, it was necessary to establish the relationship $k_{g}\left(1 / p_{\text {avg }}\right)$. A sample relationship between the permeability coefficients $k_{g}$ of the sample N3 and nitrogen, as a function of reverse average pressure, for various stress values and the corresponding sample porosities, is presented in Figure 6.

As the value of the permeability coefficients $k_{g}$ decreases with an increase in the average gas pressure within the sample, the relationship $k_{g}\left(1 / p_{\text {avg }}\right)$ rises. According to the measurement procedure, the values of the $k_{g}$ coefficients-determined experimentally on the basis of Equation (5)were matched with the linear Equation (6) by means of the least squares method. On the basis of the obtained equations, it was possible to determine the Klinkenberg permeability parameters $k_{\infty}$ and $b$ for all the investigated samples. 


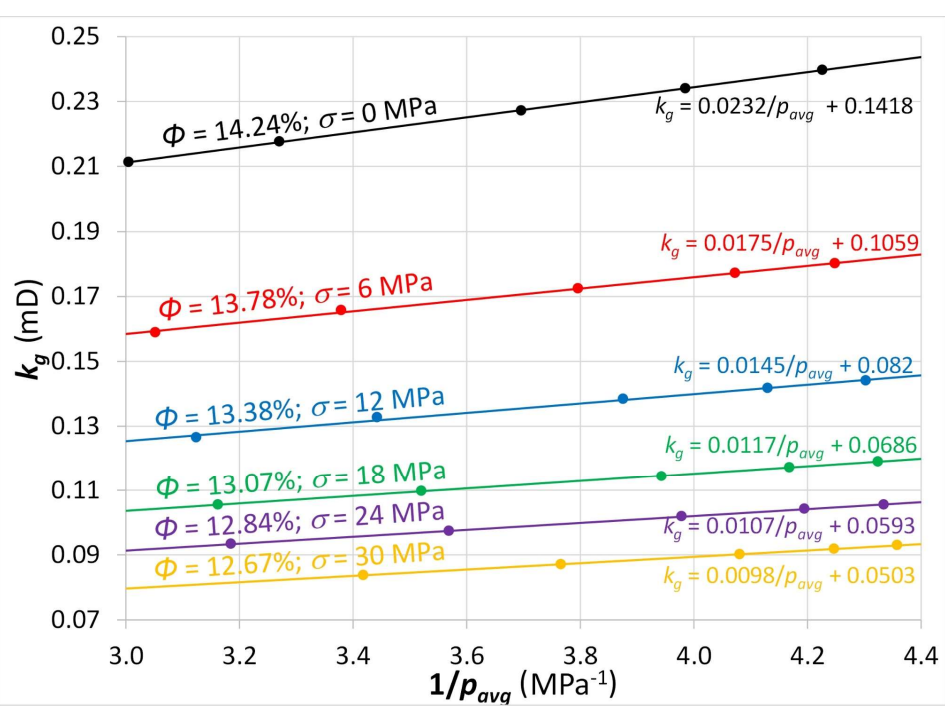

Figure 6. The relationship between the permeability coefficients $k_{g}$ of the sample N3 and nitrogen, as a function of the reverse nitrogen average pressure $p_{a v g}$, for various stress $\sigma$ values and the corresponding sample porosities $\phi$.

\subsection{The Klinkenberg Permeability Parameters $k_{\infty}$ and $b$}

A majority of studies of the permeability of coal under stress focus on the reduction in the value of the parameters describing the permeability, occurring as a result of applying effective stress to a coal sample [57-59]. However, it is extremely important to separate the impact of the applied effective stress on a change in coal porosity from the impact of the applied effective stress on a change in coal permeability. It is obvious that applying stress to a sample results in a change in its porosity [23]. If reduction in coal permeability, occurring as a result of reduction of its porosity, equals permeability reduction occurring as a result of applying stress to a coal sample, then change in the sample's pore structure (mainly reduction of porosity) directly influences the sample's permeability change. Effective stress, in this particular case, would only have an indirect effect on a change in coal's permeability. Such an effect was suggested by Ma et al. [60], which investigated the impact of changes in the porosity of a granular coal sample on the permeability of that sample. Here, the change in the porosity was generated solely by reduction of the free pore space between grains, and not by applying stress.

While describing the permeability of a porous medium, many researchers limit themselves to using Darcy permeability due to simple, linear solution to Equation (5). However, in the case of porous media characterized by low permeability - in particular, in the case of bituminous coal under effective stress-applying Darcy permeability is inappropriate [61] due to the occurrence of the slippage effect identified by Klinkenberg.

The main objective of the present paper was to investigate the impact of the changes in stress on the porosity of coal, and the reduction/increase in the value of the Klinkenberg permeability parameters $k_{\infty}$ and $b$ from the Equation (6) resulting from these changes. The values of the Klinkenberg permeability parameters on coal samples N1-N4 using nitrogen are presented in Table 3, and the values obtained during the tests performed on the samples M1-M4 using methane are presented in Table 4. 
Table 3. The values of the Klinkenberg permeability parameters on coal samples N1-N4 using nitrogen.

\begin{tabular}{|c|c|c|c|c|}
\hline Sample & Stress (MPa) & Porosity (\%) & $\begin{array}{l}\text { Permeability Coefficient } k_{\infty} \\
(\mathrm{mD})\end{array}$ & $\begin{array}{c}\text { Slippage Factor } b \\
\text { (MPa) }\end{array}$ \\
\hline \multirow{6}{*}{ N1 } & 0.00 & 18.87 & 0.816 & 0.072 \\
\hline & 6.26 & 18.24 & 0.611 & 0.061 \\
\hline & 12.12 & 17.72 & 0.492 & 0.076 \\
\hline & 18.27 & 17.24 & 0.428 & 0.078 \\
\hline & 24.40 & 16.83 & 0.366 & 0.093 \\
\hline & 30.10 & 16.52 & 0.320 & 0.106 \\
\hline \multirow{6}{*}{ N2 } & 0.00 & 15.81 & 0.249 & 0.122 \\
\hline & 5.99 & 15.23 & 0.175 & 0.136 \\
\hline & 12.30 & 14.71 & 0.132 & 0.152 \\
\hline & 18.10 & 14.32 & 0.109 & 0.170 \\
\hline & 24.54 & 13.99 & 0.098 & 0.159 \\
\hline & 30.22 & 13.78 & 0.080 & 0.195 \\
\hline \multirow{6}{*}{ N3 } & 0.00 & 14.24 & 0.142 & 0.163 \\
\hline & 6.06 & 13.78 & 0.106 & 0.165 \\
\hline & 12.14 & 13.38 & 0.082 & 0.177 \\
\hline & 18.17 & 13.07 & 0.069 & 0.170 \\
\hline & 24.01 & 12.84 & 0.059 & 0.180 \\
\hline & 30.30 & 12.67 & 0.050 & 0.195 \\
\hline \multirow{6}{*}{ N4 } & 0.00 & 12.91 & 0.083 & 0.187 \\
\hline & 5.99 & 12.48 & 0.063 & 0.173 \\
\hline & 11.98 & 12.11 & 0.039 & 0.260 \\
\hline & 17.97 & 11.81 & 0.030 & 0.291 \\
\hline & 23.96 & 11.58 & 0.023 & 0.345 \\
\hline & 29.95 & 11.42 & 0.021 & 0.324 \\
\hline
\end{tabular}

Table 4. The values of the Klinkenberg permeability parameters on coal samples M1-M4 using methane.

\begin{tabular}{|c|c|c|c|c|}
\hline Sample & Stress (MPa) & Porosity (\%) & $\begin{array}{l}\text { Permeability Coefficient } k_{\infty} \\
\text { (mD) }\end{array}$ & $\begin{array}{c}\text { Slippage Factor } b \\
\text { (MPa) }\end{array}$ \\
\hline \multirow{6}{*}{ M1 } & 0.00 & 14.41 & 0.01031 & 0.171 \\
\hline & 6.01 & 14.02 & 0.00835 & 0.188 \\
\hline & 12.05 & 13.69 & 0.00755 & 0.185 \\
\hline & 18.25 & 13.41 & 0.00713 & 0.181 \\
\hline & 24.23 & 13.18 & 0.00686 & 0.177 \\
\hline & 30.11 & 12.99 & 0.00649 & 0.174 \\
\hline \multirow{6}{*}{ M2 } & 0.00 & 11.33 & 0.00316 & 0.264 \\
\hline & 6.11 & 10.87 & 0.00291 & 0.211 \\
\hline & 12.15 & 10.48 & 0.00251 & 0.198 \\
\hline & 18.07 & 10.16 & 0.00210 & 0.204 \\
\hline & 23.98 & 9.89 & 0.00178 & 0.212 \\
\hline & 29.90 & 9.75 & 0.00154 & 0.205 \\
\hline \multirow{6}{*}{ M3 } & 0.00 & 9.97 & 0.00195 & 0.290 \\
\hline & 6.02 & 9.61 & 0.00150 & 0.295 \\
\hline & 12.12 & 9.29 & 0.00120 & 0.293 \\
\hline & 17.95 & 9.02 & 0.00104 & 0.273 \\
\hline & 23.97 & 8.79 & 0.00096 & 0.221 \\
\hline & 29.89 & 8.55 & 0.00084 & 0.228 \\
\hline \multirow{6}{*}{ M4 } & 0.00 & 9.21 & 0.00127 & 0.265 \\
\hline & 5.98 & 8.76 & 0.00089 & 0.298 \\
\hline & 12.11 & 8.37 & 0.00082 & 0.254 \\
\hline & 18.03 & 8.04 & 0.00065 & 0.272 \\
\hline & 24.08 & 7.77 & 0.00055 & 0.254 \\
\hline & 29.92 & 7.41 & 0.00052 & 0.267 \\
\hline
\end{tabular}


The values of the Klinkenberg permeability coefficient $k_{\infty}$-for all of the investigated samples using both gases-decrease with rising stress and a corresponding reduction in porosity. In the case of the tests using nitrogen, the reduction in the samples' porosity changed from $18.87 \%$ to $11.42 \%$, the value of the Klinkenberg permeability coefficient fell around 40 times, and the value of the slippage factor $b$ increased about five times. The results of the tests involving methane, in turn, showed that the reduction in the samples' porosity from $14.14 \%$ to $7.41 \%$ was accompanied by a 20 -time decline in the value of the Klinkenberg permeability coefficient $k_{\infty}$, as well as by a 1.5-time increase in the value of the slippage factor $b$. Changes in the values of the Klinkenberg permeability coefficients in relation to porosity were depicted in Figures 7 and 8.
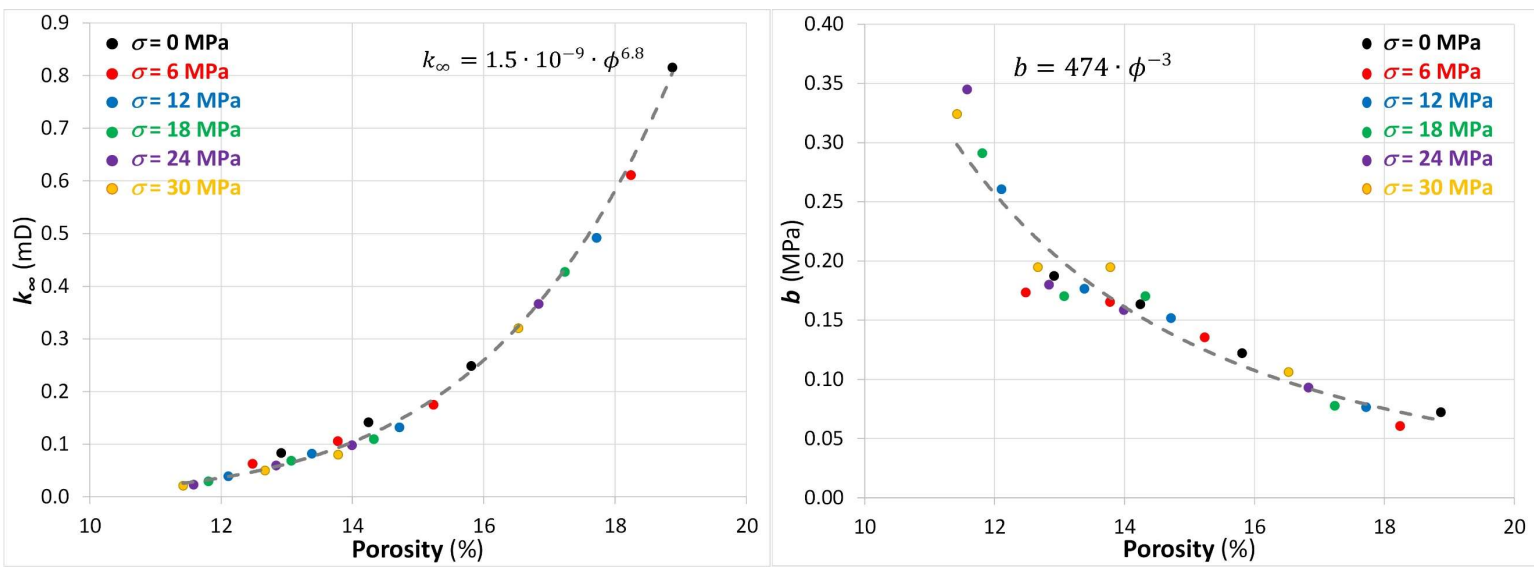

Figure 7. The relationships between the values of the Klinkenberg permeability coefficient $k_{\infty}$, and the slippage factor $b$, as a function of the porosity, obtained from the tests on the coal samples N1-N4 using nitrogen, where: $\sigma$-are the stress values; $\phi$-is the porosity.
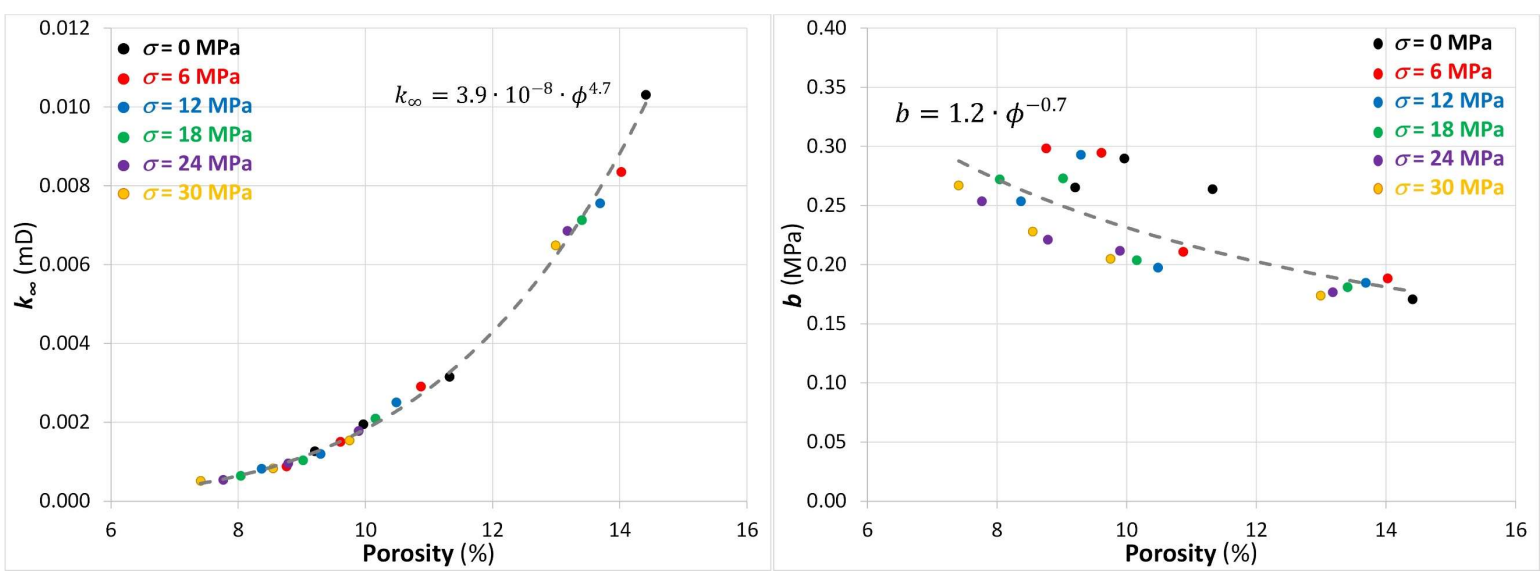

Figure 8. The relationships between the values of the Klinkenberg permeability coefficient $k_{\infty}$, and the slippage factor $b$, as a function of the porosity, obtained from the tests on the coal samples M1-M4 using methane, where: $\sigma$-are the stress values; $\phi$-is the porosity.

Assuming that coal porosity is the main factor affecting the permeability of coal, one should expect an unequivocal relationship between the coefficients $k_{\infty} \& b$ and porosity, regardless of how the porosity is achieved. During the tests, the initial porosity of the prepared sample was reduced in stages, via exerting stress on the sample during permeability measurements. Figure 7 (permeability of the samples N1-N4 to nitrogen) and Figure 8 (permeability of the samples M1-M4 to methane) present the charts illustrate the relationships between the coefficients $k_{\infty} \& b$ and porosity. In both cases, the hypothesis porosity is the dominant factor on permeability was confirmed. The relationship between both Klinkenberg permeability coefficients and porosity is described by means of power equations: $k_{\infty}=1.5 \times 10^{-9} \cdot \phi^{6.8}, b=474 \cdot \phi^{-3}$ (permeability of the samples N1-N4 to nitrogen) and 
$k_{\infty}=3.9 \times 10^{-8} \cdot \phi^{4.7}, b=1.2 \cdot \phi^{-0.7}$ (permeability of the samples M1-M4 to methane). In the case of slippage factors $b$, for measurements involving methane, the spread around the applied power fitting was considerable. This may be the result of the methane sorption processes in coal, and coal swelling caused by the methane sorption process $[62,63]$. These processes might influence the occurrence of the Klinkenberg slippage effect. In the case of the measurements on samples N1-N4 involving nitrogen - a gas with low sorption potential in relation to coal—the spread of the values of the parameter $b$ was small.

The conducted tests into the permeability of the coal briquettes, involving nitrogen and methane, showed that stress applied to a coal sample results in a change in the sample's porosity. In addition, porosity is the main factor impacting the nature of the permeability process described by the Klinkenberg Equation (6).

\subsection{The Klinkenberg Permeability Parameters Ratio to Nitrogen and Methane}

Several laboratory tests of the permeability of coal shows that the permeability of coal in relation to gases with a high adsorption potential is lower than the permeability of coal in relation to inert gases $\left(\mathrm{Ar}, \mathrm{He}, \mathrm{N}_{2}\right)[21,35]$. Figure 9 presents the relationship between the Klinkenberg permeability parameters of coal briquettes and the porosity. In the case of several samples characterized by similar porosities (area marked in green on the graph), the charts additionally show the relationship between the values of the permeability parameters $k_{\infty} \& b$ and nitrogen \& methane.
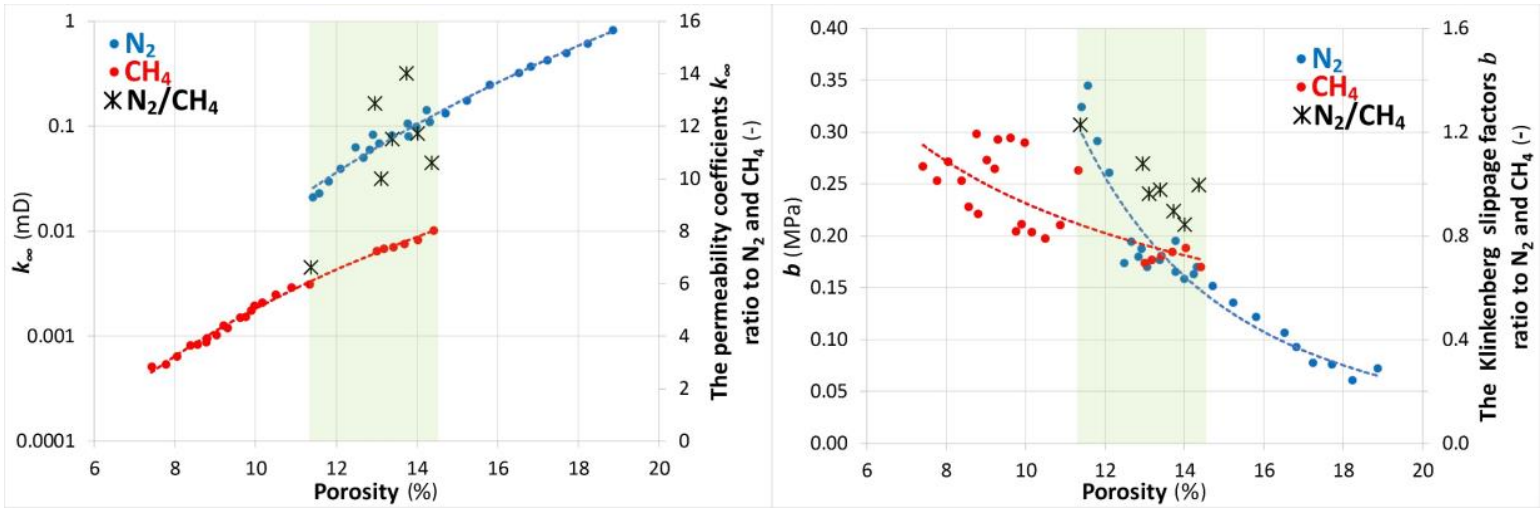

Figure 9. The relationship between the values of the Klinkenberg permeability coefficient $k_{\infty}$, and the slippage factor $b$ of coal briquettes and nitrogen \& methane as a function of porosity.

The values of the permeability coefficients $k_{\infty}$ of the coal samples in relation to $\mathrm{N}_{2}$ and $\mathrm{CH}_{4}$ were presented in a logarithmic scale. The changes in the permeability of the samples to $\mathrm{N}_{2}$ and $\mathrm{CH}_{4}$ as a function of porosity was similar; however, in the case of nitrogen, the values of $k_{\infty}$ were higher by one order of magnitude (Figure 9-left graph). The Klinkenberg slippage effect, in the case of applying nitrogen for samples with higher porosities, was small. In the case of methane, the decline in the value of the slippage factor $b$ occurring along with the increase in porosity was much smaller, which means that this effect still occurred in the entire range of the tested porosities of the coal samples.

The permeability coefficients $k_{\infty}$ ratio to $\mathrm{N}_{2}$ and $\mathrm{CH}_{4}$, for the samples with porosities of approximately $11.3 \%$, was 6.6 , whereas samples with porosities of approximately $13.7 \%$, was 14 . Therefore, the permeability of the investigated coal to nitrogen exceeded its permeability to methane by up to one order of magnitude. This may be the result of methane, as a gas characterized by a high sorption potential, causes swelling of coal, which, in turn, reduces coal permeability. The slippage factor parameter $b$, for the investigated coal material, were similar for both nitrogen and methane, and their value ratio declined from 1.2 for samples with ca. $11.3 \%$ porosity to 0.8 for samples with ca. $14 \%$ porosity. 


\section{Conclusions}

The permeability of coal depends on a number of factors, of which-as research suggests-the effective stress applied to coal is dominant. Changes in stress applied to coal alter its porosity. The main objective of the conducted research was to answer the following question: is a decline in the permeability of coal a direct effect of a decrease in coal's porosity, with stress leading solely to a change in porosity? The conducted tests-performed on briquettes characterized by various porosities and prepared from the same coal material-indicate that stress causes predominantly a change in coal porosity, which, in turn, reduces its permeability.

Specifically, the following conclusions were drawn:

- the values of the Darcy permeability coefficients $k_{g}$ decrease as the average gas pressure in a coal sample increases,

- the values of the Klinkenberg permeability coefficient $k_{\infty}$ decrease along with an increase in stress and the corresponding reduction in porosity,

- reduction of the porosity of the samples from $18.87 \%$ to $11.42 \%$ caused: (i) a 40 -time decrease (from $0.816 \mathrm{mD}$ to $0.021 \mathrm{mD}$ ) in the value of the Klinkenberg permeability coefficient $k_{\infty}$ in relation to nitrogen, and (ii) a 5-time increase (from $0.072 \mathrm{MPa}$ to $0.324 \mathrm{MPa}$ ) in the value of the slippage factor $b$,

- reduction in the porosity of the samples from $14.14 \%$ to $7.41 \%$ caused: (i) a ca. 20 -time decrease (from $0.01031 \mathrm{mD}$ to $0.00052 \mathrm{mD}$ ) in the value of the Klinkenberg permeability coefficient $k_{\infty}$ in relation to methane, and (ii) a 1.5-time increase (from $0.171 \mathrm{MPa}$ to $0.267 \mathrm{MPa}$ ) in the value of the slippage factor $b$,

- the permeability of the investigated coal to nitrogen exceeded its permeability to methane by up to one order of magnitude ( 6.6 times for the porosity of ca. $11.3 \%$, and 14 times for the porosity of ca. $13.7 \%)$,

- the slippage factor parameter $b$ for the investigated coal reached similar values using nitrogen and methane, within the investigated range of the coal briquettes' porosities,

- $\quad$ along with an increase in the porosity of briquettes, the Klinkenberg slippage effect: (i) disappeared in the case of nitrogen, (ii) and recorded a slight decline in value in the case of methane,

- the stress applied to coal samples resulted predominantly in a change of their porosity; that porosity was the main factor influencing the nature of the permeability process described by the Klinkenberg Equation (6).

- The conducted tests into the permeability of coal briquettes of various porosities demonstrate that the stress applied to samples resulted predominantly in a change of the porosity of these samples. The present research shows, in an experimental manner, that the porosity is the parameter with a deciding impact on permeability as described by Klinkenberg.

Funding: The present work was financed from the resources of the National Science Centre in Poland, as part of the project entitled " $\mathrm{CO}_{2} / \mathrm{CH}_{4}$ exchange sorption in coal material under confining pressure" (Project no.: 2016/23/B/ST8/00744).

Conflicts of Interest: The author declares no conflict of interest.

\section{References}

1. Kreiner, K.; Żyła, M. Binary character of surface of coal. Gór. Geoinż. 2006, 30, 19-34.

2. Clarkson, C.R.; Bustin, R.M. The effect of pore structure and gas pressure upon the transport properties of coal: A laboratory and modelling study: 1. Isotherms and pores volume distributions. Fuel 1999, 78, 1333-1344. [CrossRef]

3. Mastalerz, M.; Gluskoter, H.; Rupp, J. Carbon dioxide and methane sorption in high volatile bituminous coals from Indians, USA. Int. J. Coal Geol. 2004, 60, 43-55. [CrossRef] 
4. Mahajan, O.P.; Walker, J.P.L. Porosity of Coal and Coals Products; Karr, C., Jr., Ed.; Academic Press: New York, NY, USA, 1978; Volume 1, p. 125.

5. Ettinger, J.L. Solubility of Methane Contained in Coal Deposits. Arch. Min. Sci. 1990, 33, 35.

6. Battistutta, E.; van Hemert, P.; Lutynski, M.; Bruining, H.; Wolf, K.H. Swelling and sorption experiments on methane, nitrogen and carbon dioxide on dry Selar Cornish coal. Int. J. Coal Geol. 2010, 84, 39-48. [CrossRef]

7. Żyła, M. Układ węgiel kamienny-metan w aspekcie desorpcji i odzyskiwania metanu z gazów kopalnianych; Uczelniane Wydawnictwo Naukowo-Badawcze: AGH, Kraków, 2000.

8. Gawor, M.; Skoczylas, N. Sorption rate of carbon dioxide on coal. Transp. Porous Media 2014, 101, $269-279$. [CrossRef]

9. Pajdak, A. Parameters of $\mathrm{N}_{2}$ and $\mathrm{CO}_{2}$ adsorption onto coal at various temperatures. In Proceedings of the 18th International Multidisciplinary Scientific Geoconference SGEM, Albena, Bulgaria, 30 June-9 July 2018; pp. 633-640.

10. Chattaraj, S.; Mohanty, D.; Kumar, T.; Halder, G. Thermodynamics, kinetics and modeling of sorption behaviour of coalbed methane-A review. J. Unconv. Oil Gas Resour. 2016, 16, 14-33. [CrossRef]

11. Kudasik, M. Results of comparative sorption studies of the coal-methane system carried out by means of an original volumetric device and a reference gravimetric instrument. Adsorpt. J. Int. Adsorpt. Soc. 2017, 23, 613-626. [CrossRef]

12. Larsen, J.W. The effects of dissolved $\mathrm{CO}_{2}$ on coal structure and properties. Int. J. Coal Geol. 2004, 57, 63-70. [CrossRef]

13. Karacan, C.O. Swelling-induced strains internal to a stressed coal associated with $\mathrm{CO}_{2}$ sorption. Int. J. Coal Geol. 2007, 72, 209-220. [CrossRef]

14. Hol, S.; Peach, C.J.; Spiers, C.J. Applied stress reduces the $\mathrm{CO}_{2}$ sorption capacity of coal. Int. J. Coal Geol. 2011, 85, 128-142. [CrossRef]

15. Day, S.; Fry, R.; Sakurovs, R. Swelling of coal in carbon dioxide, methane and their mixtures. Int. J. Coal Geol. 2012, 93, 40-48. [CrossRef]

16. Zhang, Y.; Lebedev, M.; Sarmadivaleh, M.; Barifcani, A.; Rahman, T.; Iglauer, S. Swelling effect on coal micro structure and associated permeability reduction. Fuel 2016, 182, 568-576. [CrossRef]

17. Han, F.; Chen, G.; Liu, Z.; Yang, J. Correlation of swelling and sorption properties of block coal sample. Fuel 2017, 188, 452-461. [CrossRef]

18. Zang, J.; Wang, K. Gas sorption-induced coal swelling kinetics and its effects on coal permeability evolution: Model development and analysis. Fuel 2017, 189, 164-177. [CrossRef]

19. Walker, J.P.L.; Verma, S.K.; Rivera-Utrilla, J.; Davis, A. Densities, porosities and surface areas of coal macerals as measured by their interaction with gases, vapours and liquids. Fuel 1988, 67, 1615-1623. [CrossRef]

20. Reucroft, P.J.; Patel, H. Gas-induced swelling in coal. Fuel 1986, 65, 816-820. [CrossRef]

21. Siriwardane, H.J.; Gondle, R.K.; Smith, D.H. Shrinkage and swelling of coal induced by desorption and sorption of fluids: Theoretical model and interpretation of field project. Int. J. Coal Geol. 2009, 77, 90-102. [CrossRef]

22. Czerw, K. Methane and carbon dioxide sorption/desorption on bituminous coal—Experiments on cubicoid sample cut from the primal coal lump. Int. J. Coal Geol. 2011, 85, 72-77. [CrossRef]

23. Li, Y.; Tang, D.; Xu, H.; Meng, Y.; Li, J. Experimental research on coal permeability: The roles of effective stress and gas slippage. J. Nat. Gas Sci. Eng. 2014, 21, 481-488. [CrossRef]

24. Majewska, Z.; Majewski, S.; Ziętek, J. Swelling and acoustic emission behaviour of unconfined and confined coal during sorption of $\mathrm{CO}_{2}$. Int. J. Coal Geol. 2013, 116-117, 17-25. [CrossRef]

25. Xu, B.X.; Li, X.F.; Haghighi, M.; Ren, W.N.; Du, X.Y.; Chen, D.; Zhai, Y.Y. Optimization of hydraulically fractured well configuration in anisotropic coal-bed methane reservoirs. Fuel 2013, 107, 859-865. [CrossRef]

26. Aguilera, R.F.; Ripple, R.D.; Aguilera, R. Link between endowments, economics and environment in conventional and unconventional gas reservoirs. Fuel 2014, 126, 224-238. [CrossRef]

27. Wang, Z.; Pan, J.; Hou, Q.; Niu, Q.; Tian, J.; Wang, H.; Fu, X. Changes in the anisotropic permeability of low-rank coal under varying effective stress in Fukang mining area, China. Fuel 2018, 234, 1481-1497. [CrossRef]

28. Chen, Z.; Pan, Z.; Liu, J.; Connell, L.D.; Elsworth, D. Effect of the effective stress coefficient and sorption-induced strain on the evolution of coal permeability: Experimental observations. Int. J. Greenh. Gas Control 2011, 5, 1284-1293. [CrossRef] 
29. Konecny, P.; Kozusnikova, A. Influence of stress on the permeability of coal and sedimentary rocks of the Upper Silesian basin. Int. J. Rock Mech. Min. Sci. 2011, 48, 347-352. [CrossRef]

30. Perera, M.S.A.; Ranjith, P.G.; Choi, S.K. Coal cleat permeability for gas movement under triaxial, non-zero lateral strain condition: Atheoretical and experimental study. Fuel 2013, 109, 389-399. [CrossRef]

31. Meng, Z.; Li, G. Experimental research on the permeability of high-rank coal under a varying stress and its influencing factors. Eng. Geol. 2013, 162, 108-117. [CrossRef]

32. Zou, J.; Chen, W.; Yang, D.; Yu, H.; Yuan, J. The impact of effective stress and gas slippage on coal permeability under cyclic loading. J. Nat. Gas Sci. Eng. 2016, 31, 236-248. [CrossRef]

33. Liu, Q.; Zhang, K.; Zhou, H.; Cheng, Y.; Zhang, H.; Wang, L. Experimental investigation into the damage-induced permeability and deformation relationship of tectonically deformed coal from Huainan coalfield, China. J. Nat. Gas Sci. Eng. 2018, 60, 202-213. [CrossRef]

34. Huy, P.Q.; Sasaki, K.; Sugai, Y.; Ichikawa, S. Carbon dioxide gas permeability of coal core samples and estimation of fracture aperture width. Int. J. Coal Geol. 2010, 83, 1-10. [CrossRef]

35. Somerton, W.H.; Söylemezoglu, I.M.; Dudley, R.C. Effect of stress on permeability of coal. Int. J. Rock Mech. Min. Sci. Geomech. Abstr. 1975, 12, 129-145. [CrossRef]

36. Durucan, S.; Edwards, J.S. The effects of stress and fracturing on permeability of coal. Min. Sci. Technol. 1986, 3, 205-216. [CrossRef]

37. Pajdak, A.; Godyń, K.; Kudasik, M.; Murzyn, T. The use of selected research methods to describe the pore space of dolomite from copper ore mine, Poland. Environ. Earth Sci. 2017, 76, 389. [CrossRef]

38. Dake, L.P. Fundamentals of Reservoir Engineering. No. 8. Amsterdam: Developments in Petroleum Science; Elsevier Science BV: New York, NY, USA, 1978.

39. Klinkenberg, L.J. The permeability of porous media to liquids and gases. In Proceedings of the API Drilling and Production Practice, New York, NY, USA, 1 January 1941; pp. 200-213.

40. Scheidegger, A.E. The Physics of Flow through Porous Media, 3rd ed.; University of Toronto Press: Toronto, ON, Canada, 1974.

41. Skoczylas, N.; Kudasik, M.; Wierzbicki, M.; Murzyn, T. New instruments and methods for analysing the coal-methane system. Stud. Geotech. Mech. 2015, 37, 85-91. [CrossRef]

42. Skoczylas, N. Analyzing the parameters of the coal-gas system using a low-cost device based on a flowmeter. Adsorpt. Sci. Technol. 2015, 33, 769-782. [CrossRef]

43. Skoczylas, N. Determining the gas permeability coefficient of a porous medium by means of the bubble-counting flow meter. Meas. Sci. Technol. 2015, 26, 085004. [CrossRef]

44. Kudasik, M. The manometric sorptomat-An innovative volumetric instrument for sorption measurements performed under isobaric conditions. Meas. Sci. Technol. 2016, 27, 035903. [CrossRef]

45. Kudasik, M.; Skoczylas, N. Analyzer for measuring gas contained in the pore space of rocks. Meas. Sci. Technol. 2017, 28, 105901. [CrossRef]

46. Skoczylas, N.; Wierzbicki, M.; Kudasik, M. A simple method for measuring basic parameters of the coal-methane system under mining conditions. J. Min. Sci. 2018, 3, 186-197.

47. Kudasik, M.; Pajdak, A.; Skoczylas, N. The validation process of the method of balancing gas contained in the pore space of rocks via rock comminution. Arch. Min. Sci. 2018, 63, 989-1005.

48. Kanciruk, A. SGM-1C measuring instruments: their modifications and examples of application. Elektron. Podzesp. Zastos. Electron. 1998, 12, 20-22.

49. Kudasik, M.; Skoczylas, N.; Sobczyk, J.; Topolnicki, J. Manostat-An accurate gas pressure regulator. Meas. Sci. Technol. 2010, 21, 085402. [CrossRef]

50. Topolnicki, J.; Kudasik, M.; Skoczylas, N.; Sobczyk, J. Low cost capillary flow meter. Sens. Actuators A Phys. 2009, 152, 146-150. [CrossRef]

51. Komorek, J.; Lewandowska, M.; Probierz, K. Peculiarities of petrographic composition of coking coals in southwest part of Upper Silesian Coal Basin (Poland) as a result of thermal metamorphism influence. Arch. Min. Sci. 2010, 55, 783-798.

52. UNECE International Classification of In-Seam Coals; UNECE Geneva: New York, NY, USA, 1998; p. 41.

53. Zhou, Y.; Zhao, J. Advances in Rock Dynamics and Applications; CRC Press: Boca Raton, FL, USA, 2011.

54. Pan, Z.; Connell, L.D. A theoretical model for gas adsorption-induced coal swelling. Int. J. Coal Geol. 2007, 69, 243-252. [CrossRef] 
55. Chareonsuppanimit, P.; Mohammad, S.A.; Robinson, R.L.; Gasem, K.A.M. Modeling gasadsorption-induced swelling and permeability changes in coals. Int. J. Coal Geol. 2014, 121, 98-109. [CrossRef]

56. Wang, K.; Du, F.; Wang, G. Investigation of gas pressure and temperature effects on the permeability and steady-state time of chinese anthracite coal: An experimental study. J. Nat. Gas Sci. Eng. 2017, 40, 179-188. [CrossRef]

57. Harpalani, S.; Chen, G. Influence of gas production induced volumetric strain on permeability of coal. Geotech. Geol. Eng. 1997, 15, 303-325. [CrossRef]

58. Ma, Q.; Harpalani, S.; Liu, S. A simplified permeability model for coalbed methane reservoirs based on matchstick strain and constant volume theory. Int. J. Coal Geol. 2011, 85, 43-48. [CrossRef]

59. Kumar, H.; Elsworth, D.; Liu, J.; Pone, D.; Mathews, J.P. Optimizing enhanced coalbed methane recovery for unhindered production and $\mathrm{CO}_{2}$ injectivity. Int. J. Greenh. Gas Control 2012, 11, 86-97. [CrossRef]

60. Ma, D.; Miao, X.; Wu, Y.; Bai, H.; Wang, J.; Rezania, M.; Huang, Y.; Qian, H. Seepage properties of crushed coal particles. J. Pet. Sci. Eng. 2016, 146, 297-307.

61. Wu, Y.; Pruess, K.; Persoff, P. Gas Flow in Porous Media with Klinkenberg Effects. Transp. Porous Media 1998, 32, 117-137. [CrossRef]

62. Majewska, Z.; Majewski, S.; Ziętek, J. Swelling of coal induced by cyclic sorption/desorption of gas: Experimental observations indicating changes in coal structure due to sorption of $\mathrm{CO}_{2}$ and $\mathrm{CH}_{4}$. Int. J. Coal Geol. 2010, 83, 475-483. [CrossRef]

63. Baran, P.; Zarębska, K.; Bukowska, M. Expansion of hard coal accompanying the sorption of methane and carbon dioxide in isothermal and non-isothermal processes. Energy Fuels 2015, 29, 1899-1904. [CrossRef]

(C) 2019 by the author. Licensee MDPI, Basel, Switzerland. This article is an open access article distributed under the terms and conditions of the Creative Commons Attribution (CC BY) license (http:/ / creativecommons.org/licenses/by/4.0/). 